\author{
Cadernos de \\ ESTUDOS LINGḯĺSTICOS - (57.1), Campinas, Jan./Jun. 2015
}

\title{
DE CLÍTICO À CONCORDÂNCIA: O CASO DOS ACUSATIVOS DE TERCEIRA PESSOA EM PORTUGUÊS BRASILEIRO
}

\author{
JAIRO NUNES \\ $\mathrm{USP} / \mathrm{CNPq}$
}

\begin{abstract}
RESUMO: Uma das propriedades sintáticas que mais caracteriza o português brasileiro (PB) é a perda dos clíticos acusativos de terceira pessoa $o(s) / a(s)$ e seus alomorfes. Como amplamente documentado na literatura, em PB esses elementos estão associados a escolarização e registros formais de fala e escrita. Neste trabalho investigo o estatuto teórico desses elementos após serem "acrescentados" à gramática nuclear do PB via escolarização sintática. Como base em seu intrincado padrão de colocação, argumentarei que $o(s) / a(s)$ não são incorporados como clíticos nos registros relevantes de $\mathrm{PB}$, mas como marcas de concordância (de objeto).
\end{abstract}

Palavras-chave: clítico acusativo de terceira pessoa; concordância; português brasileiro.

ABSTRACT: One of the main syntactic properties that characterizes Brazilian Portuguese (BP) is the loss of the third person accusative clitics $o(s) / a(s)$ and their allomorphs. As is well documented in the literature, in BP these elements are associated with formal education and formal registers of speech and writing. In this paper I investigate the theoretical status of these elements once they are "added" to the core grammar of BP through schooling. Based on their intricate pattern of syntactic placement, I argue that $o(s) / a(s)$ are not acquired as clitics in the relevant registers of BP, but rather as (object) agreement markers.

Keywords: third person accusative clitics; agreement; Brazilian Portuguese.

\section{INTRODUÇÃ̃O}

Uma das propriedades marcantes que distinguem o português brasileiro (PB) do português europeu (PE) é o uso dos clíticos acusativos de terceira pessoa $o(s), a(s)$ e seus alomorfes $-l o(s),-l a(s)$ e $-n o(s),-n a(s)$ (vejam-se e.g. Omena 1978, Duarte 1986, 1989, Galves 1989, 2001, Corrêa 1991, Kato 1993,

${ }^{1}$ Uma versão preliminar da hipótese deste artigo foi apresentada na Universidade Estadual de Campinas durante o II Ciclo de Encontros do ForMa, em homenagem aos 80 anos de Mary A. Kato. Agradeço aos participantes do encontro por sugestões e comentários.

Gostaria de aproveitar a oportunidade e expressar a minha grande alegria em participar deste volume dos Cadernos em homenagem à Mary. Com toda a sua humildade e profunda humanidade, a Mary é para todos os que a conhecem uma constante fonte de inspiração e exemplo a ser seguido. Sinto-me particularmente afortunado por ter sempre podido contar com o seu apoio em minha jornada linguística e pessoal. Muito obrigado por tudo, Mary querida! 
2011, Nunes 1993, Cyrino 1997, Kato e Raposo 2005 e Kato, Cyrino e Corrêa 2009). Enquanto não parece haver diferença significativa entre esses clíticos e os demais clíticos no repertório de $\mathrm{PE}$, em $\mathrm{PB}$ os clíticos acusativos de terceira pessoa (doravante, CA3P) se diferenciam dos demais em vários aspectos. $\mathrm{O}$ mais saliente deles é que ao contrário dos clíticos pronominais me e te, por exemplo, ${ }^{2}$ que são adquiridos cedo num processo canônico de aquisição, os CA3P são adquiridos bem tardiamente via escolarização ou simplesmente não são adquiridos, ou seja, não fazem parte da gramática de um grande número de falantes de PB. Como consequência, o uso de CA3P em PB está associado a maior grau de escolarização, registro formal e língua escrita, como amplamente demonstrado na literatura.

Neste trabalho examino o estatuto teórico dos CA3P nos idioletos e registros relevantes, buscando responder à seguinte pergunta: Se os CA3P são "acréscimos" adquiridos via escolarização, qual é o estatuto gramatical desses acréscimos dentro do sistema? Procurarei mostrar que, ao contrário do que se poderia esperar, não se trata de uma simples ampliação do inventário de clíticos presentes na gramática nuclear dos falantes de $\mathrm{PB} .^{3} \mathrm{~A}$ hipótese que pretendo explorar é que os chamados CA3P na verdade são analisados em PB como marcas de concordância (de objeto).

O trabalho está organizado da seguinte forma. Na seção 2, apresento a hipótese de Nunes (1993) para o desaparecimento dos CA3P na gramática nuclear do PB. Na seção 3, discuto aspectos relevantes de sua distribuição em PB atual. Na seção 4, apresento a análise "híbrida" de Ormazabal e Romero (2013) para os clíticos em espanhol, segundo a qual somente os CA3P são de fato clíticos, sendo os demais marcas de concordância de objeto. $\mathrm{Na}$ seção 5, também exploro uma análise híbrida para os clíticos do PB, mas com uma proposta às avessas do que Ormazabal e Romero defendem para o espanhol. A seção 6 conclui o trabalho.

${ }^{2}$ Neste trabalho vou restringir a base de comparação aos clíticos pronominais me e te, por se comportarem da mesma maneira e aparentemente estarem presentes em todos os dialetos do PB. Os demais clíticos do PB têm restrições de natureza diversa (veja-se e.g. Kato, Martins e Nunes a sair) que impedem uma comparação uniforme com os CA3P. O clítico vos, por exemplo, não ocorre em nenhum dialeto do $\mathrm{PB}$, enquanto o clítico lhe é dialetalmente restrito: é inexistente no dialeto mineiro, mas presente no dialeto baiano, por exemplo. Os clíticos reflexivos, a depender da construção, podem também ser omitidos em vários dialetos (vejam-se e.g. d'Albulquerque 1984, Nunes 1995). Já o clítico pronominal nos está se tornando restrito a registros formais, presumivelmente em função da competição com a gente, que está se tornando a forma mais frequente para expressar a primeira pessoal do plural (veja-se e.g. Lopes 2003). Finalmente, se passivo se tornou uma forma arcaizante em PB (vejam-se Galves 1986, Nunes 1990, 1991) e se impessoal/indefinido exibe várias idiossincrasias de colocação (veja-se Martins e Nunes a sair).

${ }^{3}$ Estou aqui empregando a expressão gramática nuclear do $P B$ para designar propriedades gramaticais que estão presentes em todos os dialetos do PB e que emergem no curso normal do processo de aquisição, sendo independentes de escolarização. 
2. A PERDA DOS CA3P NA GRAMÁTICA NUCLEAR DO PORTUGUÊS BRASILEIRO

Nunes (1993) levanta a hipótese de que o desaparecimento dos CL3P em PB atual está relacionado a uma mudança fonológica afetando os clíticos de uma maneira geral que ocorreu em PB. Além de exibir diferenças sintáticas quanto à posição dos clíticos, PE e PB também diferem em relação ao seu parsing fonológico. Como defendido por Carvalho (1989), clíticos são fonologicamente enclíticos em PE, mas fonologicamente proclíticos em PB. Isso explica, entre outras coisa, por que clíticos podem iniciar uma sentença em PB (p.e. Me telefone!), mas não em PE. Com base nessa distinção de direcionalidade de cliticização fonológica (da direita para a esquerda em PE moderno e da esquerda para a direita em PB moderno), Nunes (1993) levanta a questão de qual seria a direção de cliticização em estágios mais antigos do português.

Três fatos podem servir de base para se responder a essa pergunta. Em primeiro lugar, não se atestam dados com clíticos em posição de início de sentença em português antigo (veja-se e.g. Martins 1994). Em segundo lugar, de acordo com Williams (1938/1991:155), “os pronomes $o, a$, os e as não raro se contraíam com a terminação do verbo, e.g., vejo-o > vejo." Finalmente, em português antigo o contexto morfológico para a realização dos CA3P como $l o(s) / l a(s)$ e $n o(s) /$ $n a(s)$ (veja-se seção 3.1 abaixo para uma discussão mais detalhada) não estava circunscrito a verbos. Como Williams (1938/1991:156-157) nota, “[q]uando as formas acusativas eram adjungidas a quase qualquer palavra precedente terminada em $r$ ou $s$ em português arcaico, e.g., macar, melhor, senhor, por (per), Deus, des, mais, pois, todos, todas, etc., as mesmas modificações se verificavam, e.g. melho-la fezestes (CB, N. $\left.{ }^{\circ} 85\right)$; pola veer (CB, N. $\left.{ }^{\circ} 177\right)$; pello fazer cavalleiro (Graal, 40): Deu-lo sabe poi-la vi (CB, N. ${ }^{\circ}$ 177); a toda-lo el diria (Cd'A, II, 178); o bon rei en seu podê'-la ten (CA, N. $\left.{ }^{\circ} 460\right)$ )"; "[q]uando as formas acusativas eram adjungidas a umas poucas palavras terminadas em $\mathrm{n}$, a mesma modificação ocorria, e.g., bem-no (CA, N. $\left.{ }^{\circ} 29\right)$; nõ na (Crest, 30); que'-no (CA, N. ${ }^{\circ} 256$ ); sena (CV, N. $\left.{ }^{\circ} 37\right) "{ }^{4}$ A ausência de clíticos em posição de início de sentença e o fato de os CA3P em português antigo serem sensíveis ao condicionamento fonológico precedente indicam que em português antigo a direção de cliticização fonológica também era da direita para a esquerda, como em PE atual..$^{5}$ Assumindo que isso esteja essencialmente correto, a conclusão a que se chega é que foi o PB que mudou em relação à direção de cliticização fonológica.

Nunes (1993) argumenta que essa mudança teve um impacto substancial na aquisição dos CA3P em PB. A ideia chave é que a alomorfia exibida pelos CL3P na história do português (p.e. o/lo/no) revela uma estrutura silábica mais complexa

\footnotetext{
${ }^{4}$ Casos semelhantes também são documentados por Mattos e Silva (1989).

${ }^{5}$ Isso obviamente não quer dizer que a colocação sintática dos clíticos se manteve a mesma entre o português antigo e o PE moderno. Para discussão relevante, vejam-se e.g. Martins 1994 e Galves, Britto e Paixão de Sousa 2005.
} 
do que geralmente se assume. Os CA3P das línguas românicas evoluíram dos demonstrativos latinos illum/illam/illud. Ao contrário de outras línguas românicas, que preservaram o fonema /1/ do demonstrativo latino em suas séries de CA3P (como le em francês e lo em espanhol, por exemplo), o português restringe a realização de uma consoante no onset da sílaba de seus CA3P (/1/ ou /n/) a determinados contextos morfo-fonologicamente condicionados (veja-se seção 3.1 abaixo). Nunes propõe que a sílaba dos CA3P $o(s) / a(s)$ tem uma posição de onset subespecificada e que, em português antigo e PE moderno, o licenciamento dessa posição se dá via cliticização fonológica da direita para a esquerda, podendo resultar em alomorfia. Por outro lado, depois que PB assumiu a direcionalidade inversa (da esquerda para a direita), esse onset deixou de ser legitimado, o que levou ao desaparecimento dos CA3P em PB moderno. Em outras palavras, a mudança da direcionalidade de cliticização fonológica em PB impossibilitou que os CA3P fossem adquiridos do mesmo modo que em PE. Os alomorfes $l o(s)$, la $(s)$, $n o(s)$ e $n a(s)$, que são sensíveis ao contexto precedente, não permitiram às gerações de crianças que já haviam adquirido a direcionalidade de cliticização fonológica como sendo da esquerda para a direita uma análise consistente para os CA3P como um todo. Diante desse cenário, Nunes (1993) conclui, os CA3P não mais foram adquiridos como parte da gramática nuclear do PB e seu desaparecimento, por sua vez, abriu caminho para duas outras mudanças que caracterizam o PB atual: a possibilidade de objetos nulos em contextos de ilha e a possibilidade de pronomes fracos de terceira pessoa na posição de objeto (vejam-se e.g. Galves 1989, 2001, Kato 1993 e Cyrino 1997), como ilustrado em (1). ${ }^{6}$

(1) a. Esse filme, todo mundo [que assistiu Ø] chorou.

b. Eu vi ele ontem.

A manutenção dos $\mathrm{CA} 3 \mathrm{~B}$ em $\mathrm{PB}$ atual se deve fundamentalmente à ação normativa da escola, como fartamente documentado na literatura. Em seu estudo sobre a realização de objeto anafórico em PB, Corrêa (1991), por exemplo, reporta que os CA3P tem frequência muito baixa na fala de universitários $(11.2 \%)$ e estão totalmente ausentes da fala de analfabetos. Em relação à escrita, Corrêa

${ }^{6}$ A obsolescência dos CA3P em PB afetou inclusive expressões idiomáticas. Como nota Nunes (2007), o clítico $o$ em (ia) não é mais interpretado com masculino singular, pois (ia) pode ser usado para um destinatário do sexo feminino. Além disso, (ib), sem o clítico, é a alternativa mais frequente para (ia). No entanto, (ib) está em desacordo com uma estrutura envolvendo um objeto nulo, pois objetos nulos em PB não podem ser intrepretados como $2^{\mathrm{a}}$ pessoa. Isso indica que a queda do clítico de (ia) provocou uma reanálise da própria expressão idiomática e a interpretação de (ib) como um xingamento endereçado a um interlocutor não pode ter por base o objeto nulo. Evidência disso é que PB também admite a interjeição em (ic). É interessante observar que em PE (ia) só pode é compatível com um intercolutor do sexo masculino e (ib) e (ic) são agramaticais justamente por terem um objeto nulo no interior de uma ilha (a oração relativa).

(i) a. Vai à puta que o pariu!

b. Vai à puta que pariu!

c. Puta que pariu 
$\overline{\text { mostra que embora a frequência dos CA3P atinja um pico de } 85,7 \% \text { na escrita de }}$ universitários, seu uso só tem início a partir da 3\% $/ 4^{\mathrm{a}}$ série, quando os alunos já estão com idade entre 9 e 10 anos.

Surge, portanto, a pergunta do que exatamente se aprende na escola. A resposta mais óbvia seria que o inventário de clíticos acusativos do $\mathrm{PB}$ deveria incluir também os CA3P, à semelhança do que se encontra em PE. Esse pode até ser o objetivo do sistema escolar, mas não é o que de fato é adquirido. Como mostrarei na próxima seção, os chamados CA3P em PB não só diferem dos demais clíticos em relação a quando são adquiridos e como são adquiridos, mas também em relação à sua distribuição sintática, o que põe em xeque a sua própria análise enquanto clíticos.

\section{IDIOSSINCRASIAS DOS CA3P EM PB}

Nesta seção apresento as propriedades dos CA3P para os falantes de PB que incorporaram esses elementos via escolarização. ${ }^{7}$

\subsection{Alomorfia}

Em PE moderno, os CA3P $o(s) / a(s)$ são realizados como -lo(s)/-la(s) quando enclíticos a um verbo terminado em $/ \mathrm{r} / \mathrm{ou} / \mathrm{s} /$ e como -no(s)/-na(s) quando enclíticos a um verbo terminado em ditongo nasal, como ilustrado em (2)-(4).

(2) a. comprar + o $\rightarrow$ comprá- lo

(3) a. compras + o $\rightarrow$ compra- lo

b. compramos $+\mathrm{o} \rightarrow$ compramo- lo

c. pus $+\mathrm{o} \rightarrow$ pu-lo

d. fiz + o $\rightarrow$ fi-lo

(4) a. compraram + o $\rightarrow$ compraram-no

b. abrem $+\mathrm{o} \rightarrow$ abrem-no

Os padrões em (2)-(4) são igualmente produtivos em PE, mas têm comportamento bem distinto em PB. Essa diferença entre os dois dialetos decorre de vários fatores independentes. Em primeiro lugar, como se discutirá em mais detalhe na seção 3.3 abaixo, a posição sintática ocupada por clíticos é eminentemente a de ênclise ao verbo em PE (veja-se e.g. Martins 1994), mas de próclise em PB (vejam-se e.g. Pagotto 1993 e Galves, Ribeiro e Moraes 2005).

${ }^{7}$ Restringirei minha discussão a julgamentos de falantes escolarizados sobre a possibilidade de realização dos CA3P em registros de fala formal, deixando de lado uma discussão sobre escrita formal, que traz consigo fatores adicionais independentes. 
Esse fator por si só reduz drasticamente os ambientes que podem resultar nos alomorfes $-l o(s) /-l a(s)$ e -no(s)/nas $(s)$, que são dependentes de ênclise. Além disso, o PB perdeu o morfema de $2^{\mathrm{a}}$ pessoa do singular $-s$ e mesmo o fonema $/ \mathrm{s} / \mathrm{do}$ morfema de $1^{\mathrm{a}}$ pessoa do plural -mos pode ser elidido em registros informais (p.e. Nós chegamo bem na hora/Vamo lá?). ${ }^{8}$ Finalmente, uma das características mais salientes de PB não-padrão é a ausência de nasalização para marcar concordância de $3^{\mathrm{a}}$ pessoa do plural, como, por exemplo, em eles abreleles compraru (vejam-se e.g. Lemle e Naro 1977 e Scherre e Naro 1998). O resultado dessa conjunção de fatores é que, grosso modo, o padrão em (2) ocorre em registros formais tanto de língua falada quanto escrita, (4) está restrito a registros formais de língua escrita e (3) simplesmente inexiste em PB.

O padrão em (2) merece maior atenção. Duas formas verbais podem terminar em/r/ em português: o infinitivo e o futuro do subjuntivo. ${ }^{9}$ Ambas são idênticas para verbos regulares (p.e. cantar), mas podem ser diferentes para verbos irregulares (p.e. ter/tiver). Em PE, o futuro do subjuntivo desencadeia próclise e, portanto, o padrão ilustrado em (2) está restrito ao infinitivo. Em PB, por outro lado, o sincretismo envolvendo infinitivo e futuro do subjuntivo está se expandindo para verbos irregulares e sentenças como (5) abaixo são julgadas como aceitáveis. Como consequência, o padrão de alomorfia em (2) também é permitido para o futuro do subjuntivo em PB, como exemplificado em (6), com verbos regulares, e (7) com irregulares (veja-se Nunes 2011).

(5) a. Se você ver o João, me avise. $($ ver $\sim$ vir $)$

b. Quando a polícia deter os ladrões, isso vai ser novidade. (deter $\sim$ detiver)

(6) a. Se você encontrá-lo, me avise.

b. Quando a polícia prendê-los, isso vai ser novidade.

(7) a. Se você vê-lo, me avise.

b. Quando a polícia detê-los, isso vai ser novidade.

Há uma outra propriedade comum entre o infinitivo e o futuro do subjuntivo em PB que é relevante para a nossa discussão. Ambas as formas podem ser comumente realizadas sem o fonema /r/, como ilustrado em (8) abaixo. Note-se ainda que não se detecta um efeito de choque de registro se uma sentença envolver uma forma sem /r/ e uma forma com -lo, como ilustrado em (9).

(8) a. Seria bom a gente chegá na hora certa.

b. Se você chegá antes, me telefone.

\footnotetext{
${ }^{8}$ Nunes (a sair) sugere que -mos pode receber uma análise bimorfêmica em PB, com -mo como morfema de $1^{\text {a }}$ pessoa e $-s$ como morfema de plural. A queda obrigatória de $/ s /$ antes do reflexivo nos em PE como em levantamo-nos, por exemplo, parece indicar que -mos pode receber uma análise bimorfêmica também em PE.

${ }^{9}$ Estou pondo de lado verbos irregulares como querer, que também termina em $-r$ na $3^{\text {a }}$ pessoa do singular do presente do indicativo (quer).
} 
(9) Se você não comprá esse carro, eu vou comprá-lo.

Dado que a queda do morfema de infinitivo é tão comum em PB, surge então a pergunta de por que um CA3P enclítico a um infinitivo sempre tem o onset de sua sílaba realizado como /1/. Em outras palavras, por que o PB manteve parcialmente a alomorfia do sistema original, tendo em vista que os CA3P poderiam em princípio se adjungir a uma forma de infinitivo sem $/ \mathrm{r} /$, gerando sentenças como (10a) abaixo, por exemplo (10 $^{10}$ Note que não se pode atribuir a inaceitabilidade de (10a) a alguma restrição puramente segmental (a vogal do clítico seguindo uma vogal acentuada, por exemplo), pois (10b) possui o mesmo contexto.

(10) a. *Eu vou comprá-o.

b. Eu vou comprá o livro.

A inaceitabilidade de (10a) sugere que a regra de apagamento se aplica (opcionalmente) quando o morfema de infinitivo se encontra em fim de palavra, como esquematizado em (11a), e que a adjunção de um CA3P à direita do verbo na sintaxe, como em (11b), bloqueia a aplicação da regra. No componente fonológico, há então um processo de assimilação entre o morfema de infinitivo e o onset do CA3P (representado como C em (11b)), que se superficializa então como lo.

(11) a. Eu vou \#compr-a-r\# $\rightarrow$ Eu vou comprá

b. Eu vou \#compr-a-r-[Co]\# $\rightarrow$ Eu vou comprá-lo

O contraste em (12) abaixo fornece evidência independente para a ideia de que a regra de apagamento só se aplica se o morfema de infinitivo se encontrar em final de palavra.

(12) a. Eu vou cantá.

b. *O cantá dos pássaros me alegra.

(12) mostra que a regra de apagamento opera em infinitivos verbais, mas não em infinitivos nominais e isso pode ser explicado se os infinitivos nominais possuírem um morfema derivacional nulo que converte infinitivos verbais em infinitivos nominais, como esquematizado em (13) abaixo. Assim, a regra de apagamento pode se aplicar em (13a), mas não em (13b) ou no interior de compostos, como em (14).

(13) a. Eu vou [cant-a-r $]_{V}$

b. O $\left[[\text { cant-a-r }]_{\mathbf{V}}-\boldsymbol{\emptyset}\right]_{N}$ dos pássaros me alegra.

(14) a. o pôr-do-sol

b. *o pô-do-sol

${ }^{10}$ Agradeço a Raquel S. Santos pela proveitosa discussão sobre esse ponto. 
$\mathrm{O}$ fato de que o CA3P em (11b) bloqueia a regra de apagamento da mesma forma que o morfema nominalizador em (13b) nos leva à conclusão de que, do ponto de vista morfológico, o CA3P em (11b) é interpretado como fazendo parte da palavra contendo o verbo. ${ }^{11}$

\subsection{Fusão de CCAP com outros clíticos}

Em PE, com exceção do clítico se, todos os clíticos dativos podem se fundir com CA3P, como ilustrado em (15) abaixo. Por outro lado, em PB esse tipo de fusão é simplesmente impossível.

(15) $P E$ :
a. O João não mo deu.
b. Quem to deu?
c. O João enviou-lha.
d. A Maria recomendou-no-las.
e. Eu não vo-lo direi.

A impossibilidade de sentenças como (15a) e (15b), por exemplo, nos idioletos e registros de PB que admitem CL3P é bastante intrigante, pois nesse contexto os CL3P poderiam legitimar o onset de suas sílabas via fusão com o clítico dativo, mesmo estando numa posição de próclise ao verbo. Na verdade, $\mathrm{PB}$ só permite (marginalmente) a co-ocorrência de clíticos dativos e CA3P numa mesma oração em casos como em (16) abaixo (veja-se Nunes 2011). Crucialmente, nesses casos o clítico dativo ocupa uma posição de próclise ao infinitivo e o CA3P, de ênclise.

(16) $P B$ :
a. Você pode me enviá-lo por e-mail.
b. Eu não poderia te recomendá-lo, porque ele ainda não fez por merecer.

\subsection{Colocação sintática}

\subsubsection{Próclise vs. ênclise}

PE tem essencialmente um sistema enclítico de colocação sintática. $\mathrm{Na}$ ausência de desencadeadores de próclise como a negação, por exemplo, os clíticos se adjungem à direita do verbo principal ou do verbo auxiliar, como ilustrado em (17) abaixo. Já em PB os clíticos em geral se adjungem à esquerda do verbo

${ }^{11}$ Deve-se salientar que essa propriedade pode não ser intrínseca aos CA3P em PB, mas ser resultado da ênclise. Mesmo que este seja o caso, os fatos discutidos ainda são compatíveis com a proposta a ser defendida na seção 5 de que os CA3P em PB são marcas de concordância. Deixarei uma discussão mais detalhada desse ponto para uma outra ocasião. 
principal ou do verbo auxiliar, sem necessidade de motivação independente, como exemplificado em (18). ${ }^{12}$

(17) $P E$ :
a. O João viu-te/*te viu na festa.
b. O João não te viu/*viu-te na festa.
c. O João tinha-me/*me tinha visto na festa.
d. O João não me tinha/*tinha-me visto na festa.

(18) $P B$ :
a. O João (não) te viu/*viu-te na festa.
b. Esse livro (não) me foi/*foi-me recomendado pelo Pedro.

Os CA3P do PB, no entanto, só se conformam parcialmente a esse padrão. Em contextos envolvendo sentenças finitas com um único verbo, como em (19a) abaixo, obtém-se o padrão esperado de próclise obrigatória. Mas em contextos envolvendo infinitivo, como em (19b), os CA3P só são licenciados em posição de ênclise. Finalmente, em contextos envolvendo futuro do subjuntivo, próclise e ênclise são possíveis, como ilustrado em (19c).

(19) $P B$
a. A Maria o viu/*viu-o na festa.
b. Não era permitido criticá-lo/*o criticar em público.
c. Se eu contratá-lo/o contratar, te ligo.

Crucialmente, a ênclise ao futuro do subjuntivo só é permitida se houver sincretismo entre infinitivo e futuro do subjuntivo, como em (19c). Nos casos de verbos irregulares que admitem sincretismo (ver seção 3.1), somente a forma sincrética permite ênclise, como ilustrado em (20) e (21).

(20) a. Se você o ver/vê-lo, me avise.

b. Se você o vir/*vi-lo, me avise.

(21) a. Quando a polícia os deter/detê-los, isso vai ser novidade.

b. Quando a polícia os detiver/*detivé-los, isso vai ser novidade.

\footnotetext{
${ }^{12}$ Conforme apontam Martins e Nunes (a sair), o clítico se impessoal/indefinido é uma exceção a esse padrão:

(i) PB:

a. Contratou-se $/ *$ Se contratou um novo professor.

b. *Deve, sem sombra de dúvida, se contratar um novo professor.

c. Deve-se, sem sombra de dúvida, contratar um novo professor.
} 


\subsubsection{Concordância e ênclise}

Vimos acima que infinitivos requerem ênclise para os CA3P e que o futuro do subjuntivo (sincrético) admite tanto ênclise quanto próclise. O quadro na verdade se torna mais complexo quando se leva em conta a flexão de concordância do verbo. No caso de infinitivo impessoal, a ênclise é obrigatória, como visto em (19c). Já no caso de infinitivo pessoal, há dois padrões: se a concordância do verbo for foneticamente realizada, somente próclise é possível (cf. (22)); por outro lado, se a concordância do verbo não tiver realização fonética, próclise se torna uma opção marginal e ênclise se torna a opção preferível (cf. (23)).

(22) a. Não seria adequado nós o recomendarmos/*recomendarmo-lo para o cargo.

b. Não seria adequado eles o recomendarem/*recomendarem-no para o cargo.

(23) Não seria adequado eu/você/a gente/ele recomendá-lo/?o recomendar para o cargo.

O futuro do subjuntivo vai na mesma direção, permitindo, porém, tanto próclise quanto ênclise quando a concordância verbal não for foneticamente realizada:

(24) a. Se nós o recomendarmos/*recomendarmo-lo para o cargo, vai parecer inadequado.

b. Se eles o recomendarem/*recomendarem-no para o cargo, vai parecer inadequado.

(25) Se eu/você/a gente/ele o recomendar/recomendá-lo para o cargo, vai parecer inadequado.

Para efeito de comparação, observe que a realização fonética da concordância em nada influencia a colocação dos demais clíticos, mantendo-se inalterado o padrão geral de próclise tanto para o infinitivo pessoal, quanto para o futuro do subjuntivo:

(26) a. Não seria adequado nós te recomendarmos/*recomendarmos-te para o cargo.

b. Não seria adequado eles me recomendarem/*recomendarem-me para o cargo.

c. Não seria adequado eu/você/a gente/ele me recomendar/*recomendarme para o cargo.

(27) a. Se nós te recomendarmos/*recomendarmos-te para o cargo, vai parecer inadequado. 
b. Se eles me recomendarem/*recomendarem-me para o cargo, vai parecer inadequado.

c. Se eu/você/a gente/ele me recomendar/*recomendar-me para o cargo, vai parecer inadequado.

\subsubsection{Clitic climbing}

Os CA3P também contrastam com os demais clíticos em relação a clitic climbing em construções envolvendo verbos auxiliares (vejam-se e.g. Figueiredo Silva 1990 e Nunes 2011). Os clíticos me e te uniformemente se adjungem à esquerda do verbo principal e clitic climbing não é permitido, como ilustrado em (28). ${ }^{13}$

(28) a. O João vai [me ver] $/ *$ O João me vai ver.

b. O João tinha [me visto]/*O João me tinha visto.

b. O João estava [me vendo]/*O João me estava vendo.

Por outro lado, o padrão de colocação dos CA3P é sensível à especificação do verbo principal. Se o verbo estiver no infinitivo, a ênclise é obrigatória; se estiver no particípio ou no gerúndio, obtém-se clitic climbing com próclise ao verbo auxiliar:

(29) a. O João vai vê-lo/*O João vai $[$ o ver $] / *$ O João o vai ver.

b. O João o tinha visto $/ *$ O João tinha [o visto].

b. O João o estava vendo/*O João estava [o vendo].

\subsubsection{Posição em início de sentença}

Finamente, ao contrário dos demais clíticos, os CA3P não podem aparecer em início de sentença:

(30) a. Me leva pra casa?

b. Te levo pra casa?

c. *O levo pra casa?

É interessante observar que os CA3P também se comportam diferentemente do clítico se indefinido (ver nota 12). Martins e Nunes (a sair) apontam que se indefinido não pode ocorrer em início de sentença, como ilustrado em (31a). Uma vez que a próclise é excluída desse ambiente, a ênclise torna-se viável, conforme se pode ver em (31b). Entretanto, no caso dos CA3P, a ênclise não está disponível como último recurso para salvar a estrutura. A alternativa de (30c) com ênclise é igualmente inaceitável, como se vê em (32).

\footnotetext{
${ }^{13}$ As passivas constituem uma exceção a esse padrão, pois verbos passivos não admitem próclise (Figueiredo Silva 1990):

(i) O livro me foi enviado ontem/*O livro foi [me enviado] ontem.
} 
(31) a. *Se contratou um novo funcionário.

b. Contratou-se um novo funcionário.

(32) *Levo-o para casa?

\subsection{Resumo}

Como vimos acima, as diferenças entre os CA3P e os demais clíticos em $\mathrm{PB}$ vão bem além do período em que sua aquisição ocorre e como ocorre (via escolarização). Em particular, os CA3P em PB são bastante sensíveis a propriedades morfológicas e fonológicas dos contextos em que ocorrem: não podem iniciar uma sentença, não podem se adjungir à esquerda de verbos nãofinitos, e só podem aparecer enclíticos a um verbo no infinitivo ou no futuro do subjuntivo se a concordância verbal não tiver realização fonética. Essa disparidade de comportamento indica que a aquisição tardia dos CA3P em PB via escolarização não tem como efeito simplesmente acrescentar mais itens ao conjunto de clíticos da gramática nuclear do PB. Parece ser mais o caso de um acréscimo de elementos de natureza diferente. Resta, assim, identificar a que classe natural os CA3P pertencem.

Esse vai ser o objetivo da seção 5. Antes, porém, discuto na próxima seção algumas assimetrias que levaram Ormazabal e Romero (2013) a propor que os elementos tradicionalmente analisados como clíticos em espanhol também não constituem uma classe uniforme, mas envolvem clíticos propriamente ditos e marcas de concordância de objeto. Na seção 5, procurarei demonstrar que uma distinção nesses moldes pode dar conta do comportamento peculiar dos CA3P em PB.

\section{CLÍTICO OU CONCORDÂNCIA: EIS A QUESTÃO}

A maioria dos trabalhos na vasta literatura sobre clíticos nas línguas românicas tem buscado prover uma análise uniforme para os clíticos como um todo, divergindo fundamentalmente sobre a caracterização de sua natureza e geração na estrutura. Abordagens que geram os clíticos em posições argumentais (e.g. Kayne 1975) naturalmente assumem uma análise em termos de movimento, enquanto análises que geram os clíticos em posição não argumental (e.g. Sportiche 1993) tendem a ser mais compatíveis com uma análise desses elementos em termos de concordância/flexão. Numa posição intermediária situam-se trabalhos que optam por uma ou outra abordagem a depender do tipo de clítico envolvido. Neste artigo, tomarei como ponto de partida para a discussão dos CA3P do PB a análise "híbrida" que Ormazabal e Romero (2013) propõem para os clíticos em espanhol.

Retomando vários contrastes entre CA3P e os demais clíticos em espanhol documentados na literatura e apontando ainda contrastes adicionais, Ormazabal 
e Romero (doravante $O \& R$ ) propõem que em espanhol padrão os CA3P são de fato clíticos, enquanto os demais clíticos se assemelham mais a marcas de concordância. ${ }^{14}$ Entre outras diferenças, os CA3P se opõem aos demais clíticos na medida em que apresentam marcação de gênero (cf. (33)), são mais restritos semanticamente (cf. (34)), não permitem redobro (cf. (35)), e não estão sujeitos ao me-lui constraint de Perlmutter (1971) (cf. (36)).

[exemplos adaptados de $O \& R$ ]

(33) a. La vimos. [la = 'a menina' $] /$ Lo vimos. [lo = 'o menino']

b. Le di el libro a Maria/a Juan. [le = Maria/Juan]

(34) a. *Ningun libro lo han vendido.

b. A ninguna estudiante le han dado el título.

(35) a. Les recomendé un libro a los estudiantes.

b. ( *La) vimos la casa.

(36) a. *Pedro te me envia.

b. Pedro te lo envia.

Seguindo Uriagereka (1988) e Rocca (1996), O\&R assumem que os CA3P são determinantes movidos, o que explica por que eles têm marca de gênero e são mais restritos semanticamente. Sendo determinantes gerados em posição argumental, os CA3P também bloqueiam a inserção de material redobrado nessa posição. Finalmente, assumindo que o me-lui constraint na verdade expressa uma restrição sobre combinações de marcas de concordância de objeto (o object agreement constraint), os CA3P estariam imunes a essa restrição, como ilustrado em (36b).

O\&R observam também que há uma grande variação dialetal em espanhol no que diz respeito à computação dos CA3P. Especialmente relevante para o presente trabalho é a reanálise que O\&R fazem da proposta de Zdrojewski (2008) para o espanhol rio-platense. Zdrojewski argumenta que o espanhol rioplatense tem dois paradigmas de determinantes/clíticos que têm propriedades sintáticas distintas, mas estão associados aos mesmos expoentes fonológicos. O\&R reinterpretam a proposta Zdrojewski em termos da distinção entre clíticos e concordância: os CA3P que não permitem redobro seriam determinantes, como em espanhol padrão, e os CA3P que permitem redobro seriam marcas de concordância.

\footnotetext{
${ }^{14}$ O\&R mostram que essa abordagem dá conta também da intricada variação envolvendo clíticos de terceira pessoa tanto no espanhol peninsular, quanto no espanhol americano.
} 
A possiblidade de redobro em si não é uma propriedade relevante para o $\mathrm{PB}$, já que os clíticos em geral não permitem redobro nesta língua. ${ }^{15}$ Entretanto, a possibilidade de CA3P serem analisados como marcas de concordância se mostra bastante adequada também para o PB, como veremos na seção abaixo.

\section{DERIVANDO AS PROPRIEDADES DOS CA3P EM PB}

Vimos acima que os CA3P têm comportamento bastante diferente dos demais clíticos tanto em PB como em espanhol. Para o espanhol, O\&R argumentam que essas diferenças estão calcadas na diferença entre clíticos e marcas de concordância. Nesta seção, argumento que uma análise com base em tal distinção pode também ser estendida ao PB. Mais precisamente, procurarei mostrar que os CA3P em PB são marcas de concordância de objeto e sua distribuição básica se segue de três condições, relacionadas ao seu estatuto de concordância: (i) $o(s) / a(s)$ só se associam a formas verbais que independentemente podem portar marcas de concordância; (ii) $o(s) / a(s)$ e concordância de sujeito competem pela mesma posição morfológica e a concordância de sujeito tem prioridade; (iii) uma configuração não-local de concordância só pode ser ativada se as posições locais estiverem indisponíveis.

Consideremos então como essas condições interagem de modo a derivar as complexas distinções apresentadas na seção 3 .

\subsection{A necessidade de um hospedeiro concordante}

Se $o(s) / a(s)$ é uma marca de concordância em PB, espera-se que o núcleo a que esses elementos se adjungem possa independentemente ter flexão de concordância. Segue-se daí o contraste entre $o(s) / a(s)$ e os demais clíticos ilustrado abaixo:

(37) a. O João tinha [me visto].

b. *O João tinha [o visto].

(38) a. O João está [te vendo].

b. *O João está [o vendo].

Particípios perfectivos e gerúndios não se flexionam em PB. Isso em nada afeta a colocação sintática de me e te, por exemplo. Enquanto clíticos, me e te

${ }^{15}$ Em alguns dialetos do $\mathrm{PB}$, os clíticos me e te aparentemente podem ser redobrados, como exemplicado em (ia) e (ib) abaixo. Mesmo nesses dialetos, $o(s) / a(s)$ não admitem redobro, como ilustrado em (ic).

(i) $\% \mathrm{~PB}$ :
a. A Maria me convidou eu.
b. Eu te vi você.
c. *Eu o vi ele/o João. 
podem perfeitamente se procliticizar a um verbo no particípio ou no gerúndio, como se vê em (37a) e (38a). Por outro lado, $o(s) / a(s)$ em sua condição de marca de concordância não podem se adjungir a um elemento que independentemente não permite concordância, como se vê em (37b) e (38b). A derivação dessas sentenças pode, no entanto, levar a um resultado lícito se $o(s) / a(s)$ se moverem e se procliticizarem a uma forma verbal que admite concordância, como ilustrado em (39b) e (40b).

(39) a. *O João me tinha visto.

b. O João o tinha visto.

(40) a. *O João te está vendo.

b. O João o está vendo.

(39) e (40) também revelam que clitic climbing em PB é uma operação de último recurso, só desencadeada por questões de convergência. Assim, se as derivações de (37a) e (38a) convergem sem clitic climbing, as derivações de (39a) e (40a) são bloqueadas. O mesmo arrazoado se aplica ao contraste em (41) abaixo: se a derivação de (41a) converge sem clitic climbing (veja-se seção 3.1), a derivação com clitic climbing em (41b) é bloqueada. Observe que embora a concordância de sujeito em (41) seja realizada junto ao verbo auxiliar, infinitivos em PB podem ser flexionados e, portanto, o infinitivo em (41a) não repele a marca de concordância realizada como $l o$.

(41) a. O João vai cumprimentá-lo.

b. *O João o vai cumprimentar.

Evidência independente para essa proposta é fornecida pelos dados em (42) e (43).

(42) a. *Ter [a encontrado] na reunião surpreendeu o João.

b. Tê-la encontrado na reunião surpreendeu o João.

(43) a. *Tendo [a encontrado] na reunião, o João foi direto ao assunto.

b. *Tendo-a encontrado na reunião, o João foi direto ao assunto.

Como o particípio perfectivo não admite concordância, a adjunção de a ao verbo principal é bloqueada tanto em (42a) quanto em (43a). Em (42b) clitic climbing pode salvar a derivação pois o auxiliar está no infinitivo e o infinitivo em português pode ter concordância. Esse não é, no entanto, o caso de (43b): como o gerúndio não admite concordância (cf. (38b)), clitic climbing só faz reinstaurar o problema que havia em relação ao verbo principal.

Como deveríamos esperar, esse contraste não vai afetar os clíticos me e te, que simplesmente se adjungem ao verbo principal em ambos os casos: 
(44) a. Ter [me/te encontrado] na reunião surpreendeu o João.

b. Tendo [me/te encontrado] na reunião, o João foi direto ao assunto.

\subsection{A competição com outras marcas de concordância}

Assumindo que clitic climbing em (41b) é bloqueado porque infinitivos em princípio podem ter flexão de concordância e, portanto, são compatíveis com $o(s) / a(s)$, surge a pergunta de por que a próclise ao infinitivo não é permitida, como ilustrado em (45b) abaixo. Afinal de contas, o PB é essencialmente um sistema proclítico, como se vê pelo contraste entre (45a) e (46), e simplesmente não é o caso que o está sempre sujeito a um padrão excepcional de ênclise, como ilustrado em (47).

(45) a. O João vai [me cumprimentar].

b. * O João vai [o cumprimentar].

(46) a. *O João vai cumprimentar-me.

b. *O João vai-me cumprimentar.

(47) a. *O João tinha-o visto.

b. *O João está-o vendo.

Ao contrário do que possa parecer, os contrastes entre (41a) e (45b), por um lado, e entre (39b)/(40b) e (47), por outro, se seguem, sim, da natureza de $o(s) / a(s)$ como marca de concordância em PB. Enquanto marcas de concordância, seria natural esperar que $o(s) / a(s)$ competissem pelas mesmas posições morfológicas que outras marcas de concordância. Em PB, as marcas de concordância de sujeito são realizadas como sufixos verbais. Assim, essa deveria ser a realização canônica de $o(s) / a(s)$ a não ser que essa posição sufixal já esteja ocupada pela marca de concordância de sujeito. Em (41a), a concordância de sujeito é realizada junto ao auxiliar, deixando vaga a posição sufixal de concordância do infinitivo. Portanto, por paradoxal que possa parecer à primeira vista, $o$ em (41a) ocupa a posição de sua realização canônica e a derivação com próclise ao infinitivo em (45b) é devidamente excluída. No caso de (39b) e (40b), o não pode se adjungir ao verbo principal, pois, como vimos, particípios e gerúndios não dispõem de posições morfológicas para abrigar concordância em PB. Já adjunção ao auxiliar finito é em princípio permitida. Entretanto, como a posição sufixal já está ocupada pela concordância de sujeito, a concordância de objeto não pode ser realizada como sufixo (cf. (47)), restando como única alternativa de realização a posição de próclise ao auxiliar (cf. (39b) e (40b)).

Evidência independente para essa análise é fornecida pelo intricado padrão de colocação de $o$ em contexto de infinitivo e futuro do subjuntivo. ${ }^{16}$ Como

\footnotetext{
${ }^{16}$ Recorde-se que clíticos como me e te exibem um padrão uniforme de próclise ao infinitivo ou futuro do subjuntivo (cf. (26) e (27)).
} 
Cadernos de ESTUDOS LINGḯISTICOS (57.1) - Jan./Jun. 2015

vimos na seção 3.3.3, infinitivos impessoais requerem ênclise (cf. (48)), enquanto infinitivos pessoais requerem próclise se a concordância de sujeito tiver realização fonética (cf. (49)), mas preferem ênclise se não tiver (cf. (50)).

(48) Não era permitido criticá-lo/*o criticar em público.

(49) a. Não seria adequado nós o recomendarmos/*recomendarmo-lo para o cargo.

b. Não seria adequado eles o recomendarem/*recomendarem-no para o cargo.

(50) Não seria adequado eu/você/a gente/ele recomendá-lo/?o recomendar para o cargo.

A variação da posição ocupada por $o$ em (48)-(50) pode ser explicada da seguinte forma. Como (48) envolve infinitivo impessoal, não há concordância de sujeito. A posição sufixal está, portanto, disponível para abrigar $o$ e somente ênclise é admissível. O contrário ocorre em (49): a posição sufixal está foneticamente realizada pela concordância de sujeito e a próclise se torna, então, obrigatória. Já o padrão em (50) reflete uma potencial ambiguidade morfológica. A visão tradicional é que a forma recomendar em (50) envolve um morfema zero de concordância de sujeito. Assumindo que o morfema zero ocupa uma posição sufixal, como os demais morfemas de concordância de sujeito, o não poderia ocupar então essa posição e a próclise é licenciada. Em outras palavras, a próclise em (50) seria paralela à próclise de $o$ a um verbo finito (cf. (19a)). Alternativamente, o infinitivo em (50) pode também ser analisado como uma forma default, sem morfema de concordância. Enquanto forma default, recomendar em (50) tem sua posição de concordância sufixal disponível, permitindo, assim, ênclise de $o$. O fato de a ênclise em (50) ser preferível à próclise sugere que, com o enfraquecimento geral da concordância em PB, a interpretação do infinitivo sem marcas abertas de concordância como forma default está se tornando a análise canônica para os falantes de PB. ${ }^{17}$

A mesma explicação se estende ao futuro do subjuntivo. A presença de uma marca explícita de concordância de sujeito bloqueia a ênclise, como se vê em (51) abaixo (=(24)), e somente próclise é admissível. Em relação a (52) $(=(25))$, a ambiguidade relevante é entre uma forma finita (o futuro do subjuntivo) e a forma infinitiva default. Enquanto forma finita, recomendar em (52) presumivelmente se

${ }^{17}$ É de se observar que o enfraquecimento da concordância verbal em PB afeta também os infinitivos pessoais, que podem permitir sujeitos lexicais sem realização de concordância em dialetos não-padrão (veja-se e.g. Pires 2006), como ilustrado em (i).

(i) $\% \mathrm{~PB}$ :

a. O Pedro e a Maria fazer isso foi uma surpresa.

b. Foi uma falta de sorte nós levar um gol no último minuto. 
comporta como as demais formas finitas do PB, portando concordância de sujeito (nesse caso, realizado como morfema zero) e repelindo a ênclise/sufixação do morfema de concordância de objeto $o$. Isto implica que a possibilidade de ênclise em (52) se deve a uma outra estrutura, a saber, a estrutura com a forma infinitiva default, que, como vimos acima, admite ênclise.

(51) a. Se nós o recomendarmos/*recomendarmo-lo para o cargo, vai parecer inadequado.

b. Se eles o recomendarem/*recomendarem-no para o cargo, vai parecer inadequado.

(52) Se eu/você/a gente/ele o recomendar/recomendá-lo para o cargo, vai parecer inadequado.

Evidência para o fato de que a ênclise em (52) é licenciada pela forma default e não pela forma de futuro do subjuntivo homófona é que, no caso de verbos irregulares, apenas a forma default é compatível com ênclise, como se pode ver em $(53)(=(20))$ e $(54)(=(21))$.

(53) a. Se você o ver/vê-lo, me avise.

b. Se você o vir/*vi-lo, me avise.

(54) a. Quando a polícia os deter/detê-los, isso vai ser novidade.

b. Quando a polícia os detiver/*detivé-los, isso vai ser novidade.

Em suma, o intricado padrão de colocação de $o(s) / a(s)$ encontra uma explicação bastante simples se esses elementos forem marcas de concordância de objeto que competem pela posição morfológica tradicionalmente reservada à concordância (de sujeito).

\subsection{Co-ocorrência de clíticos uma mesma oração}

Como o espanhol (cf. (36b)), o PB está sujeito ao me-lui constraint e não admite a co-ocorrência de clíticos de primeira e segunda pessoa associados a um mesmo verbo, como exemplificado em (55a) abaixo. Mas diferentemente do espanhol (cf. (36a)) e do português europeu (cf. (15)), o PB não admite nem a sequência dativo-o $(s) /(a(s)$ (cf. (55b)), nem a alternativa envolvendo fusão (cf. $(55 \mathrm{c}))$.

(55) a. *O João me te/te me recomendou.

b. *A Maria me/te o recomendou

c. *A Maria mo/to recomendou

A agramaticalidade de $(55 \mathrm{c})$ em princípio pode ser atribuída às diferenças independentes entre me e te, por um lado, e $o(s) / a(s)$, por outro. Se em PB os 78 
primeiros são clíticos e os últimos, marcas de concordância, a impossibilidade de fusão entre eles pode decorrer de sua diferente natureza gramatical, associada, por exemplo, a um maior ou menor grau de integração lexical ao núcleo a que se associam. Por sua vez, a agramaticalidade de $(55 \mathrm{~b})$ pode estar associada à agramaticalidade de ênclise de $o(s) / a(s)$ a formas finitas, como em (56) abaixo. Assumindo que os clíticos em (55b) formam um constituinte morfológico com o núcleo a que se adjungem, tanto em (55b) quanto em (56) o aparece dentro de um constituinte morfológico se seguindo a um conjunto de traços- $\phi$ - o clítico em (55b) e a concordância de sujeito em (56). Se essa sequência ferir alguma condição morfológica de boa formação em PB, a inesperada impossibilidade de (55b) encontraria uma explicação.

(56) Eu o vi/*vi-o ontem.

Embora não seja claro o que exatamente leva à agramaticadade de (55b) e (55c) em PB e certamente essa questão merece uma investigação mais aprofundada, sentenças como (57) abaixo (=(16)) sugerem que as restrições sejam de natureza morfológica. Em (57) me/te e $o$ co-ocorrem, mas não em posições morfologicamente adjacentes: o clítico aparece em posição proclítica e $o$ em posição enclítica. ${ }^{18}$

(57) $P B$ :
a. Você pode [me enviá-lo] por e-mail.
b. Eu não poderia [te recomendá-lo], porque ele ainda não fez por merecer.

\subsection{Herança residual}

Finalmente, retomemos a restrição à posição de início de sentença ilustrada em $(58)(=(30))$.

(58) a. Me leva pra casa?

b. Te levo pra casa?

c. *O levo pra casa?

Embora $o$ se comporta de maneira diferente que me e te em (58), há motivos para se pensar que esse contraste não está calcado em suas diferentes naturezas

${ }^{18}$ Recorde-se que apenas infinitivos permitem ênclise de $o(s) / a(s)$ em PB (veja-se seção 3.3.1). Assim, sentenças como (i) abaixo são excluídas pelas razões discutidas anteriormente, a saber, a competição/adjacência entre $o(s) / a(s)$ e a concordância de sujeito (veja-se seção 5.2). A gramaticalidade das sentenças em (ii), com um pronome fraco de terceira pessoa na posição de objeto, reforça a ideia de que o problema de sentenças como (i) é de natureza morfológica.

(i) a. *A Maria me recomendou-o.

b. *O João te recomendou-a.

(ii) a. A Maria me recomendou ele.

b. O João te recomendou ela. 
enquanto marca de concordância e clítico. Em primeiro lugar, a próclise de $o$ em (58c) está totalmente condizente com o fato de o verbo levar estar flexionado e portar concordância de sujeito. Uma vez que a concordância de sujeito já ocupa uma posição sufixal, só resta à marca de concordância $o$ a posição de próclise ao verbo. Isso fica claro quando a restrição sobre a posição inicial é controlada. Como podemos ver em (59), a próclise é obrigatória:

\section{(59) Eu o levo/*levo-o para casa.}

Em segundo lugar, não parece haver nenhuma razão sintática ou morfológica para que a realização do morfema de concordância seja sensível à existência de material fonológico precedente.

Embora esse seja um ponto que carece de uma investigação mais aprofundada, gostaria de sugerir que essa restrição se segue de razões fonológicas. Assumindo com Nunes (1993) que a sílaba de $o(s) / a(s)$ tem um onset subespecificado, esse onset deveria ser licenciado (inclusive via elisão) pelo contexto anterior. Isso fica transparente no caso dos alomorfes $-\mathrm{lo}(s) / l a(s)$, que são dependentes da presença de um verbo no infinitivo (ou futuro do subjuntivo sincrético) no contexto imediatamente precedente. Sendo assim, se não houver contexto segmental precedendo $o(s) / a(s)$, o onset de suas sílabas não é licenciado e a derivação não converge em PF. ${ }^{19}$

Poderíamos nos perguntar por que, no processo de aquisição tardia de $o(s) / a(s)$ via escolarização, a antiga subespecificação do onset desses elementos é preservada. Em outras palavras, por que não se aprende simplesmente que esses elementos são monossílabos sem onset, como os artigos definidos homófonos, por exemplo? Creio que a resposta se encontra na robustez do input. Em seu estudo sobre a variação entre clítico acusativo, pronome lexical e categoria vazia de terceira pessoa em PB, Duarte (1989) documenta que em 40 horas de gravação de entrevistas com 5 informantes, 4 horas de episódios de novelas de televisão e 4 horas de entrevistas de televisão, apenas 97 "clíticos" foram registrados. Desses, 39 são proclíticos e 58 enclíticos, o que deveria parecer estranho tendo em vista o sistema proclítico do PB. Duarte, no entanto, esclarece que dos 58 enclíticos “apenas 3 se pospõem ao gerúndio ou a um tempo simples do indicativo; os 55 restante seguem o infinitivo, o que revela certa preferência pela forma lo sobre aquela que se constrói com um único fonema" (p. 21). Como os alomorfes -lo(s)/ $l a(s)$, que requerem independentemente uma análise de $o(s) / a(s)$ com um onset

\footnotetext{
${ }^{19}$ Essa sugestão parece ir ao encontro da proposta de Arregi e Nevins (2014) de que a ausência de uma regra elsewhere para inserção de items de vocabulário pode resultar em inefabilidade, gerando paradigmas defectivos. No presente caso, há dois contextos que determinam a realização das marcas de concordância de objeto: o mais restrito especifica o contexto precedente como o morfema de infinitivo e o mais geral simplemente requer que haja contexto precedente. Não havendo uma regra de elsewhere, não se especifica qual a realização das marcas de concordância de objeto quando não há um contexto precedente. Portanto, quando ocupam a posição de início de sentença, os chamados CA3P do português brasileiro se tornam inefáveis, impedindo que a derivação convirja em PF.
} 
Cadernos de ESTUDOS LINGǘISTICOS (57.1) - Jan./Jun. 2015

subespecificado, são os que têm frequência mais elevada no input, os aprendizes adquirem essa propriedade e rejeitam sentenças em que não há material segmental precedendo $o(s) / a(s)$.

\section{CONSIDERAÇÕES FINAIS}

É consenso na literatura sobre o PB que os chamados clíticos acusativos de terceira pessoa caíram em desuso, estando associados a registro formal e alto nível de escolarização. Surge então a pergunta sobre o que de fato se aprende/adquire via escolarização. Definitivamente, não pode ser que $o(s) / a(s)$ são clíticos, pois esses elementos têm uma distribuição muito distinta de me e te, por exemplo, como visto na seção 3. Com base no trabalho de Ormazabal e Romero (2013), procurei argumentar que $o(s) / a(s)$ são marcas de concordância (de objeto) nos registros do PB que os admitem. Explica-se, assim, por que $o(s) / a(s)$ só podem se adjungir a uma forma que independentemente pode portar concordância e por que esses elementos competem com a concordância de sujeito por uma posição sufixal.

Se essa proposta estiver no caminho correto, estará também condizente com o fato de que boa parte do processo de escolarização formal é devotada à concordância do português padrão. Alguém poderia objetar que as gramáticas tradicionais e a escola em geral não tratam $o(s) / a(s)$ como concordância, mas como clíticos. Isso é de fato verdade, mas também é verdade que as gramáticas tradicionais e as aulas de português na escola não atentam para o fato de que em $\mathrm{PB}$, ao contrário de $\mathrm{PE}, o(s) / a(s)$ não têm a mesma distribuição sintática que clíticos como me e te. Em outras palavras, temos aqui um belo exemplo do argumento da pobreza de estímulo no que se refere à aquisição da linguagem, pois há um grande fosso entre o que se ensina na escola sobre $o(s) / a(s)$ e o que é de fato internalizado pelos falantes que os adquirem.

\section{$\overline{\text { REFERÊNCIAS BIBLIOGRÁFICAS }}$}

ARREGI, K.; NEVINS, A. (2014). A monoradical approach to some cases of disuppletion. Theoretical Linguistics 40, p. 311-330.

CARVAlHO, J. B. de. (1989). Phonological conditions on Portuguese clitic placement: on syntactic evidence for stress and rhythmical patterns. Linguistics 27, p. 405-436.

CORRÊA, V. ( 1991). O objeto direto nulo no português do Brasil. Dissertação de mestrado, Universidade Estadual de Campinas.

CYRINO, S. (1987). O objeto nulo no português do Brasil: um estudo sintático-diacrônico. Londrina: Editora UEL.

D’ALBULQUERQUE, A. (1984). A perda dos clíticos num dialeto mineiro. Tempo Brasileiro 78/79, p. $97-121$. 
NUNES - De Clítico a concordância: o caso dos Acusativos...

DUARTE, M. E. L. (1986). Variação e sintaxe: clítico acusativo, pronome lexical e categoria vazia no português do Brasil. Dissertação de mestrado, Pontifícia Universidade Católica de São Paulo.

DUARTE, M. E. L. (1989). Clítico acusativo, pronome lexical e categoria vazia no português do Brasil. In TARALLO, F. (org.). Fotografias Sociolinguísticas. Campinas: Pontes/Editora da UNICAMP, p. 19-34.

FIGUEIREDO SILVA, M. C. (1990). Les clitiques em portugais du Brésil: note pour une étude. Ms., Université de Genève.

GALVES, C. (1986). Aluga-(se) casas: im problema de sintaxe portuguesa na teoria de regência e vinculação. Campinas: Preedição 2.

GALVES, C. (1989). O objeto nulo no português brasileiro: percurso de uma pesquisa. Cadernos de Estudos Lingüísticos 17, p. 65-90.

GALVES, C. (2001). Ensaios sobre as gramáticas do português. Campinas: Editora da UNICAMP.

GALVES, C.; RIBEIRO, I.; TORRES MORAIS, M. A. (2005). Syntax and orphology in the placement of clitics in European and Brazilian Portuguese. Journal of Portuguese Linguistics 4.2, p.143177.

KATO, M. A. (1993). The distribution of pronouns and null elements in object position in Brazilian Portuguese. In ASHBY, W.; PERISSINOTTO, M. M. G.; RAPOSO, E. P. (Org.). Linguistic perspectives on the Romance Languages. Amsterdam/Philadelphia: John Benjamins, p. 225235.

KATO, M. A. (2011). A natureza do objeto nulo e do nome nulo no português europeu e no português brasileiro. Revista Intercâmbio, v. XXIII, p. 13-27.

KATO, M. A.; CYRINO, S.; CORRÊA, V. (2009). Brazilian Portuguese and the recovery of lost clitics through schooling. In PIRES, A.; ROTHMAN, J. (org.) Minimalist inquiries into child and adult language acquisition: case atudies across Portuguese. Berlin/New York: Mouton De Gruyter. p. $245-272$.

KATO, M. A.; MARTINS, A. M.; NUNES, J. (a sair). The syntax of Portuguese. Cambridge: Cambridge University Press.

KATO, M. A.; RAPOSO, E. P. (2005). Obje(c)tos e artigos nulos: similaridades e diferenças entre o português europeu e o português brasileiro. In: MOURA, D. (org.) Reflexões sobre a sintaxe do português. Maceió: Edufal, p. 73-96

KAYNE, R. S. French syntax: the transformational cycle. Cambridge, Mass.: MIT Press.

LEMLE, M.; NARO, A. J. (1977). Competências básicas do português. Rio de Janeiro: MOBRAL/ Fundação Ford.

LOPES, Célia. (2003). A inserção de a gente no quadro pronominal do português. Frankfurt am Main/ Madrid: Iberoamerica:Vervuert.

MARTINS, A. M. (1994). Clíticos na história do português. Tese de doutorado, Universidade de Lisboa. 
MARTINS, A. M.; NUNES, J. (a sair). Passives and se constructions. In WETZELS, W. L.; MENUZZI, S.; COSTA, J. (org.). The handbook of Portuguese Linguistics. Malden: Wiley-Blackwell.

MATTOS e SILVA, R. V. (1989). Estruturas Trecentistas: Elementos para uma Gramática do Português Arcaico. Lisboa: Imprensa Nacional-Casa da Moeda.

NUNES, J. (1990). O famigerado se: uma análise sincrônica e diacrônica das construções com se apassivador e indeterminador. Dissertação de mestrado, Universidade Estadual de Campinas.

NUNES, J. (1991). Se apassivador e se indeterminador: o percurso diacrônico no português brasileiro. Cadernos de Estudos Lingüisticos 20, p. 33-58.

NUNES, J. (1993). Direção de cliticização, objeto nulo e pronome tônico na posição de objeto em português brasileiro. In ROBERTS, I.; KATO, M. A. (org). Português brasileiro: uma viagem diacrônica. Campinas: Editora da UNICAMP, p. 207-222.

NUNES, J. (1995). Ainda o famigerado se. D.E.L.T.A. 11.2, p. 201-240.

NUNES, J. (2007). Triangulismos e a sintaxe do português brasileiro. In CASTILHO, A. de; TORRES MORAIS, M. A.; LOPES, R.; CYRINO, S. (org.) Descrição, aquisição and história do português brasileiro. Campinas: Pontes/FAPESP, p. 25-34.

NUNES, J. (2011). On the diachronic reanalysis of null subjects and null objects in Brazilian Portuguese: triggers and consequences. In: RINKE, E.; KUPISCH, T. (org.). The development of grammar: language acquisition and diachronic change - in honor of Jürgen M. Meisel. Amsterdam/Philadelphia: John Benjamins, p. 331-354.

NUNES, J. (a sair). Subespecificação de Traços- $\phi$ e Hiperalçamento em Português Brasileiro.

OMENA, N. (1978). Pronome pessoal de terceira pessoa; suas formas variantes em função acusativa. Dissertação de mestrado, Pontifícia Universidade Católica do Rio de Janeiro.

ORMAZABAL, J.; ROMERO, J. (2013). Objec clitics, agreement and diaclectal variation. Probus 25.2, p. 301-344.

PAGOTTO, E. (1993). Clíticos, mudança e seleção natural. In ROBERTS, I. ; KATO, M. A. (org). Português brasileiro: uma viagem diacrônica. Campinas: Editora da UNICAMP, p. 185-203.

PERLMUTTER, D. (1971). Deep and surface structure constraints in syntax. New York: Rinehart \& Winston Inc.

PIRES, A. (2006). The minimalist syntax of defective domains. Amsterdam/Philadelphia: Benjamins.

ROCCA, F. (1996). Morfemas objetivos y determinantes: los clíticos del español. Verba 23, p. 83-119.

SCHERRE, M. M. P. \& NARO, A. J. (1998). Sobre a concordância de número no português falado do Brasil. In RUFFINO, G. (org.). Dialettologia, geolinguistica, sociolinguistica. Tübingen: Max Niemeyer Verlag, p. 509-523.

SPORTICHE, D. (1996). Clitic constructions. In ROORYCK, J.; ZARING, L. (org.). Phrase Structure and the Lexicon. Dordrecht: Kluwer, p. 213-276.

URIAGEREKA, J. (1988). On government. Tese de doutorado, University of Connecticut. 
NUNES - De Clítico a concordância: o caso dos Acusativos...

WILLIAMS, E. B. (1991). From Latin to Portuguese: historical phonology and morphology of the Portuguese language. Philadelphia: University of Pennsyvalnia Press, 1938. Tradução de HOUAISS, A. Do latim ao português: fonologia e morfologia históricas da língua portuguêsa. Rio de Janeiro: Tempo Brasileiro, 5. ${ }^{\mathrm{a}}$ ed.

ZDROJEWSKI, P. (2008). Por quién doblan los clíticos. Dissertação de mestrado, Universidad Nacional de Comahue. 